\title{
Long-Term Potentiation in Hippocampus Involves Sequential Activation of Soluble Guanylate Cyclase, cGMP-Dependent Protein Kinase, and cGMP-Degrading Phosphodiesterase
}

\author{
Pilar Monfort, María-Dolores Muñoz, Elena Kosenko, and Vicente Felipo \\ Instituto de Investigaciones Citológicas, Fundación Valenciana de Investigaciones Biomédicas, 46010, Valencia, Spain
}

Previous studies indicate that cGMP is involved in long-term potentiation (LTP). However, the effects of application of tetanus to induce LTP on cGMP content and the mechanisms by which cGMP may modulate LTP have not been reported. The aim of this work was to study the time course of the changes in cGMP content and of the activity of soluble guanylate cyclase (sGC) (the enzyme that synthesizes cGMP) during LTP. Moreover, we also studied how the changes in cGMP affect cGMPdependent protein kinase (PKG) and cGMP-degrading phosphodiesterase and the possible role of these changes in LTP. Application of tetanus induced a rise in cGMP, reaching a maximum $10 \mathrm{sec}$ after tetanus. cGMP content decreased below basal levels 5 min after tetanus and remained decreased after $60 \mathrm{~min}$. Activity of SGC increased $5 \mathrm{~min}$ after tetanus and returned to basal at $60 \mathrm{~min}$. Tetanus increased the activity of cGMP-degrading phosphodiesterase at 5 and $60 \mathrm{~min}$. GMP, the product of degradation, was increased at 5 and $60 \mathrm{~min}$. Activation of phosphodiesterase and a decrease in cGMP were prevented by inhibiting PKG with Rp-8-bromoguanosine-cGMPS (Rp-8-Br-cGMPS). Inhibition of sGC [with ODQ (oxadiazolo quinoxalin-1-one) or NS 2028 (4H-8-bromo-1,2,4-oxadiazolo(3,4d)benz(b)(1,4)oxazin-1-one)], of PKG (with Rp-8-Br-cGMPS), or of cGMP-degrading phosphodiesterase [with zaprinast or MBAM (4-\{[3',4' -(methylenedioxy)benzyl]amino $\}-6$-methoxyquinazoline) ] impairs LTP. The results indicate that induction of LTP involves transient activation of SGC and an increase in cGMP, followed by activation of cGMP-dependent protein kinase, which, in turn, activates cGMP-degrading phosphodiesterase, resulting in longlasting reduction of cGMP content.

Key words: cGMP; soluble guanylate cyclase; phosphodiesterase; cGMP-dependent protein kinase; nitric oxide; long-term potentiation; NMDA receptors
Long-term potentiation (LTP) is an activity-dependent form of increased transmission efficacy at synapses. Nitric oxide plays a main role in LTP, as indicated by experiments showing that LTP is eliminated or blocked significantly by inhibitors of nitric oxide synthase (Böhme et al., 1991; O’Dell et al., 1991; Schuman and Madison, 1991; Haley et al., 1993; Doyle et al., 1996). LTP is also impaired by compounds that act as quenchers of nitric oxide, such as hemoglobin (O’Dell et al., 1991; Schuman and Madison, 1991).

Nitric oxide activates soluble guanylate cyclase (sGC), increasing the formation of cGMP. There is evidence suggesting that cGMP might be involved in LTP in hippocampus. Several groups have shown that inhibitors of SGC or cGMP-dependent protein kinase (PKG) block the induction of LTP (Zhuo et al., 1994; Blitzer et al., 1995; Boulton et al., 1995; Lu et al., 1999). However, other groups reported that this pathway is not involved in LTP (Schuman et al., 1994; Selig et al., 1996; Wu et al., 1998). Son et al. (1998) performed a series of studies and concluded that cGMP plays an important role in LTP under some circumstances but not others.

Chetkovich et al. (1993) reported that application of a high-

Received May 2, 2002; revised Sept. 10, 2002; accepted Sept. 10, 2002.

This work was supported in part by grants from the Spanish Plan Nacional de Investigación Científica, Desarrollo e Innovación Tecnológica (SAF97-0001) and from the Promoción General del Conocimiento of Ministerio de Educación y Cultura (PM98-0065 and PM99-0019). P.M. and E.K. are fellows of Generalitat Valenciana.

Correspondence should be addressed to Vicente Felipo, Laboratory of Neurobiology, Instituto de Investigaciones Citológicas, Fundación Valenciana de Investigaciones Biomédicas, Amadeo de Saboya, 4, 46010 Valencia, Spain. Email: vfelipo@ochoa.fib.es.

Copyright (C) 2002 Society for Neuroscience $0270-6474 / 02 / 2210116-07 \$ 15.00 / 0$ frequency stimulation induces a transient increase in cGMP in area CA1 of the hippocampus. However, as far as we know, the effects of application of tetanus to induce LTP on the metabolism of cGMP and the mechanisms by which cGMP may modulate LTP have not been studied in detail. The aim of this work was to study the effects of induction of LTP in hippocampal slices on the time course of the changes in the content of cGMP and of the activity of sGC (the enzyme that synthesizes cGMP). Moreover, we also studied how the changes in cGMP affect PKG and cGMP-degrading phosphodiesterase (PDE), as well as the possible role of these changes in LTP.

It is shown that application of tetanus induces a rapid transient rise of cGMP, followed by a rapid reduction to levels lower than basal values. Tetanus induces a rapid and transient activation of sGC and a sustained activation of cGMP-degrading phosphodiesterase, which is mediated by activation of cGMP-dependent protein kinase.

\section{MATERIALS AND METHODS}

Long-term potentiation in hippocampal slices. Experiments were performed using transverse hippocampal slices $(400 \mu \mathrm{m})$ from male Wistar rats (180-240 gm), as described previously (Muñoz et al., 2000). Briefly, the rat was decapitated, and its brain was rapidly removed and dropped into ice-cold standard medium (in mM): $119 \mathrm{NaCl}, 2.5 \mathrm{KCl}, 1.3 \mathrm{MgSO}_{4}$, $1 \mathrm{KH}_{2} \mathrm{PO}_{4}, 26.2 \mathrm{NaHCO}_{3}, 11$ glucose, and $2.5 \mathrm{CaCl}_{2}$ (saturated with $95 \% \mathrm{O}_{2}$ and $\left.5 \% \mathrm{CO}_{2}\right), \mathrm{pH}$ 7.4. The hippocampi were dissected, and transverse slices were obtained using a manual chopper. The slices were maintained in an interface holding chamber at room temperature (21$24^{\circ} \mathrm{C}$ ). After at least $1 \mathrm{hr}$, some slices were transferred to an open submersion-type recording chamber and perfused continuously (flow rate, $1.5-2 \mathrm{ml} / \mathrm{min}$ ) with the standard medium equilibrated with $95 \% \mathrm{O}_{2}$ and $5 \% \mathrm{CO}_{2}$. The temperature was maintained at $31 \pm 1^{\circ} \mathrm{C}$. Schaffer 
collateral-commissural fibers were stimulated with electrical square pulses of 50-100 $\mu \mathrm{A}, 40 \mu \mathrm{sec}, 0.05 \mathrm{~Hz}$ (Grass Instruments S88 stimulator) applied through bipolar microelectrodes $(5 \mathrm{M} \Omega)$ located in a set of fibers in the stratum radiatum. Once the evoked potentials were stable, basal potentials were recorded for $15 \mathrm{~min}$ as control evoked potentials. High-frequency stimulation was given to some slices to induce LTP and consisted of a tetanus of three trains $(100 \mathrm{~Hz}, 1 \mathrm{sec})$ at $20 \mathrm{sec}$ intervals. Evoked field potentials were recorded from CA1 stratum radiatum with low-resistance glass micropipettes filled with Ringer's solution. Recording micropipettes were connected to field-effect transistors, and the outputs were filtered between $1 \mathrm{~Hz}$ and $3 \mathrm{kHz}$ and amplified by CyberAmp 380 (Axon Instruments, Foster City, CA). Evoked responses were online digitized at $10 \mathrm{kHz}$ (Digidata 1200 Interface; Axon Instruments). The synaptic strength was calculated by measuring the slope of the initial phase of the field EPSP (fEPSP) using a program developed by J. Bustamante (Ramón y Cajal Hospital, Madrid, Spain). Data were normalized by referring them to the mean values of responses during the initial $15 \mathrm{~min}$ period before tetanus application. To assess the effects of different drugs [ODQ (oxadiazolo quinoxalin-1-one), NS 2028 (4H-8-bromo-1,2,4-oxadiazolo(3,4- $d$ ) benz(b)(1,4)oxazin-1-one), Rp-8-bromoguanosine-cGMPS (Rp-8-BrcGMPS), zaprinast, APV, calphostin C, nitroarginine, or $4-\left\{\left[3^{\prime}, 4^{\prime}-\right.\right.$ (methylenedioxy)benzyl]amino\}-6-methoxyquinazoline (MBAM)], these compounds were included in the perfusion medium $30 \mathrm{~min}$ before application of tetanus.

Determination of cGMP in hippocampal slices. Slices were treated as described above and were collected from the recording chamber under basal conditions and at different times after application of tetanus. Samples were homogenized immediately and sonicated in the kit (see below) assay buffer containing 4 mM EDTA. Samples were centrifuged $(12,000 \times g, 5 \mathrm{~min})$, and cGMP was measured in the supernatant using the BIOTRAK cGMP enzyme immunoassay kit from Amersham Biosciences (Arlington Heights, IL). Pellets were suspended in $0.2 \mathrm{~N} \mathrm{NaOH}$, and protein was measured using Lowry's procedure.

Determination of cGMP released to the medium by hippocampal slices. Groups of five slices were treated in the incubation chamber as described above, except that the flux of the medium was stopped just before application of tetanus to allow accumulation of cGMP released to the medium. Five minutes after application of tetanus (or after stopping the flux for basal controls), the slices were collected and placed into assay tubes containing $1 \mathrm{ml}$ of the standard medium. The medium remaining in the chamber when the slices were removed (1.0-1.2 ml) was collected to measure the cGMP accumulated during the $5 \mathrm{~min}$ after application of tetanus. The slices in the test tubes were incubated for $55 \mathrm{~min}$, with continuous equilibration with $95 \% \mathrm{O}_{2}$ and $5 \% \mathrm{CO}_{2}$. One hour after application of tetanus, the slices were removed, and cGMP accumulated in the medium was determined as above. cGMP in the slices was also measured as above.

Determination of $s G C$ activity in hippocampal slices. Slices were treated as for determination of cGMP and collected under basal conditions or 5 or $60 \mathrm{~min}$ after application of tetanus. Slices were homogenized in ice-cold buffer containing $50 \mathrm{~mm}$ HEPES at a $\mathrm{pH}$ of 7.4, $4 \mathrm{~mm}$ EDTA, $0.01 \%$ bacitracin, $50 \%$ glycerol, $250 \mathrm{~mm}$ sucrose, and $1 \mathrm{~mm}$ dithiothreitol. The homogenates were centrifuged for $45 \mathrm{~min}$ at $430,000 \times g\left(4^{\circ} \mathrm{C}\right)$, and the supernatant was used to measure the activity of sGC. To initiate the enzymatic reaction, samples were mixed rapidly with an equal volume of a buffer containing $50 \mathrm{~mm}$ HEPES at a $\mathrm{pH}$ of 7.4, $2 \mathrm{~mm}$ isobutylmethylxanthine, $4 \mathrm{~mm}$ GTP, $60 \mathrm{~mm}$ phosphocreatine, $800 \mu \mathrm{g} / \mathrm{ml}$ creatine kinase (185 $\mathrm{U} / \mathrm{mg}$ ), $1 \mathrm{mg} / \mathrm{ml}$ bovine serum albumin, and $8 \mathrm{mM} \mathrm{MnCl}_{2}$. Samples were incubated at $37^{\circ} \mathrm{C}$, and duplicate $40 \mu \mathrm{l}$ aliquots were removed from the incubation mixture at 0,5 , and $10 \mathrm{~min}$, pipetted into $100 \mu \mathrm{l}$ of $6 \%$ trichloroacetic acid (TCA), and placed on ice. After centrifugation at $12,000 \times g$ for $10 \mathrm{~min}$ at $4^{\circ} \mathrm{C}$, the supernatants were transferred to new tubes, and the TCA was extracted with diethyl ether until the $\mathrm{pH}$ in the aqueous phase was neutral. Subsequently, this phase was lyophilized and reconstituted in cGMP assay buffer. cGMP was measured using the BIOTR AK cGMP enzyme immunoassay kit from Amersham Biosciences.

Assay of cGMP-degrading phosphodiesterase activity. Phosphodiesterase activity was determined by measuring the amount of inorganic phosphate released from cGMP. GMP hydrolyzed from cGMP was converted to guanosine and phosphate with alkaline phosphatase. Two slices were homogenized in $0.3 \mathrm{ml}$ of ice-cold medium consisting of $20 \mathrm{~mm}$ Tris-HCl at a $\mathrm{pH}$ of $7.5,0.25 \mathrm{M}$ sucrose, $0.1 \mathrm{~mm}$ EDTA-K ${ }^{+}, 2 \mathrm{~mm} \mathrm{MgCl}_{2}, 0.4 \mathrm{~mm}$ phenylmethylsulfonyl fluoride, $5 \mu \mathrm{M}$ leupeptin, and $10 \mathrm{mM}$ dithiothreitol. Homogenate $(100 \mu \mathrm{l})$ was added to $300 \mu \mathrm{l}$ of the incubation medium consisting of $40 \mathrm{~mm}$ Tris- $\mathrm{HCl}$ at a $\mathrm{pH}$ of 7.5, 0.1 mm EDTA-K ${ }^{+}, 2 \mathrm{~mm}$
$\mathrm{MgCl}_{2}, 0.2 \mathrm{~mm} \mathrm{cGMP}$, and $7 \mathrm{U}$ of alkaline phosphatase. Samples were incubated for $20 \mathrm{~min}$ at $37^{\circ} \mathrm{C}$. The reaction was stopped with $0.7 \mathrm{ml}$ of a solution containing $2 \%$ ascorbic acid and $10 \%$ trichloroacetic acid in water. Samples were centrifuged for $5 \mathrm{~min}$ at $3000 \times g$. The inorganic phosphate in the supernatant was determined by measuring the formation of the blue phosphomolybdous complex at $700 \mathrm{~nm}$ as described by Baginski et al. (1974)

Determination of the effect of tetanus on the activity of cGMP-degrading phosphodiesterase. Slices were obtained and treated in the incubation chamber as described above and collected under basal conditions and 60 min after application of tetanus to determine cGMP-degrading phosphodiesterase activity as above. The effects of zaprinast $(0.5$ or $2 \mu \mathrm{M})$ and MBAM $(0.5 \mu \mathrm{M})$, selective inhibitors of cGMP-specific phosphodiesterase, of Rp-8-Br-cGMPS $(10 \mu \mathrm{M})$, an inhibitor of cGMP-dependent protein kinase, of ODQ $(10 \mu \mathrm{M})$ or NS $2028(0.5 \mu \mathrm{M})$, inhibitors of sGC, and of APV $(50 \mu \mathrm{M})$, an antagonist of NMDA receptors, were tested in some experiments. These drugs were included in the perfusion medium. Slices were incubated with the drug for $30 \mathrm{~min}$ before application of tetanus, and the drugs were maintained in the perfusion medium after tetanus until removal of the slices for determination of cGMP-degrading phosphodiesterase activity.

Determination of GMP in hippocampal slices. Slices were treated as described above and were collected from the recording chamber under basal conditions and at different times after application of tetanus. The slices were frozen immediately in liquid nitrogen and homogenized in $0.6 \mathrm{~N} \mathrm{HClO}_{4}$. The homogenates were left to stand on ice for $10 \mathrm{~min}$ and subsequently centrifuged for $15 \mathrm{~min}$ at $14,000 \times g$ at $4^{\circ} \mathrm{C}$. The pellet was used for determination of protein according to the method of Lowry. The supernatant was neutralized with $30 \% \mathrm{KOH}$ and solid potassium carbonate. After standing $10 \mathrm{~min}$ on ice, $\mathrm{KClO}_{4}$ crystals were precipitated by centrifugation as above, and the supernatant was used for determination of GMP. GMP was measured as described by Keppler and Kaiser (1985), with the modifications described by Montoliu et al. (1999). Deproteinized samples $(50 \mu \mathrm{l})$ were incubated with $30 \mu \mathrm{l}$ of reaction mixture containing $164 \mathrm{~mm}$ triethanolamine at a $\mathrm{pH}$ of $7.5,5 \mathrm{~mm}$ $\mathrm{Mg}\left(\mathrm{CH}_{3} \mathrm{CO}_{2}\right)_{2}, 0.8 \mathrm{~mm}$ phosphoenolpyruvate, $0.2 \mathrm{~mm}$ nicotinamide adenine dinucleotide phosphate (NADH), $83 \mu \mathrm{M}$ ATP, $0.9 \mu \mathrm{g}$ of pyruvate kinase, $0.45 \mathrm{mg}$ of lactate dehydrogenase, and $360 \mathrm{mg}$ of myokinase. Myokinase was added to the assay mixture to remove AMP in the sample before initiation of the GMP assay with guanylate kinase. The reaction $(80 \mu \mathrm{l})$ was started by addition of $2 \mathrm{mU}$ of guanylate kinase. After incubation for $30-40 \mathrm{~min}$ at $25^{\circ} \mathrm{C}$, the amount of nicotinic acid dehydrogenase formed was measured fluorimetrically. Excess NADH was destroyed by adding $2 \mu \mathrm{l}$ of $10 \mathrm{M} \mathrm{HCl}$. Subsequently, the solution was made $6 \mathrm{M} \mathrm{NaOH}$ by addition of $15.6 \mathrm{M} \mathrm{NaOH}$ and incubated for $60 \mathrm{~min}$ at $37^{\circ} \mathrm{C}$. The samples were diluted 10 times with distilled water, and fluorescence was measured using an excitation wavelength of $355 \mathrm{~nm}$ and an emission wavelength of $460 \mathrm{~nm}$.

Paired-pulse facilitation. Paired-pulse facilitation (Zucker, 1989) was given at $0.05 \mathrm{~Hz}$ with $25-300 \mathrm{msec}$ intervals. The paired-pulse ratio was calculated as $P_{2} / P_{1}$ (where $P_{1}$ is the slope of the first fEPSP and $P_{2}$ is the slope of the second fEPSP).

Statistical analysis. The data shown are the mean \pm SEM of the number of experiments indicated in each legend to the figures. Statistical significance was estimated with one-way ANOVA and Student's $t$ test, except for Figures 1 and 5, in which statistical analysis was performed using ANOVA and Tukey-Kramer tests. A value of $p<0.05$ was considered significant.

The experimental procedures have been approved by the Instituto de Investigaciones Citológicas and meet the guidelines of the European Union for treatment and use of experimental animals.

\section{RESULTS}

In agreement with previous reports (Boulton et al., 1995; Lu et al., 1999), we also found that inhibition of sGC with ODQ impairs LTP induced by application of tetanus (Fig. $1 A$ ), whereas it did not affect the magnitude of the postsynaptic potential induced by the low-frequency control stimulation (Fig. $1 C$ ). Moreover, NS 2028, another inhibitor of sGC, also impairs LTP (Fig. $1 B$ ). This supports a role for sGC and for cGMP in LTP under the conditions used.

We then studied the effects of tetanus on the content of cGMP in hippocampal slices. As shown in Figure $2 A$, application of 

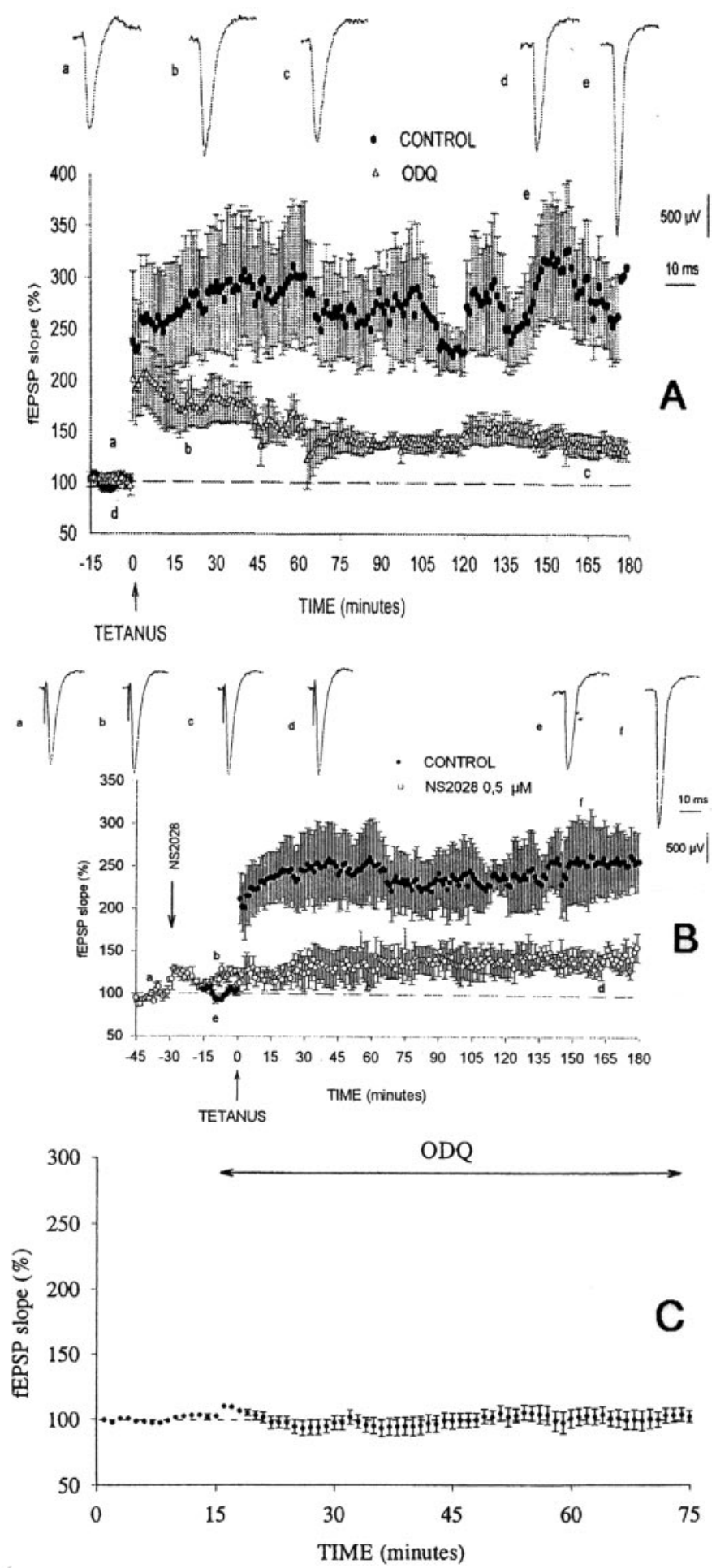

Figure 1. Inhibition of sGC impairs LTP induction in hippocampal slices. LTP in rat hippocampal slices was induced as described in Materials and Methods. Schaffer collateral-commissural pathways were stimulated with electrical pulses, and, at the time indicated by the arrow, tetanus was applied. Filled circles show the nondecremental LTP induced by tetanus in control slices (mean \pm SEM; $n=6$ ). Triangles show the fEPSP in slices treated with $10 \mu \mathrm{M}$ ODQ in $A(n=6)$ or with $0.5 \mu \mathrm{M}$ NS 2028 in $B(n=4)$, selective inhibitors of sGC. Raw evoked field potentials at the indicated times are indicated by letters: $a, b, c, \mathrm{ODQ} ; d, e$, control. Calibration: $500 \mu \mathrm{V}, 10 \mathrm{msec}$. $C$, Effect of ODQ on field EPSP without application of tetanus (mean $\pm \mathrm{SEM} ; n=9$ ).
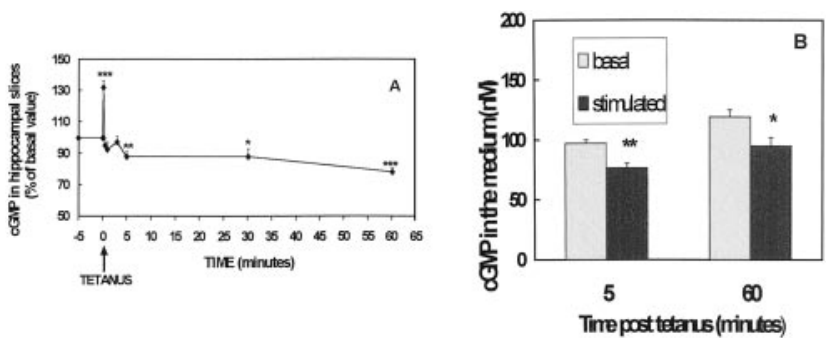

Figure 2. Effects of tetanus on cGMP in hippocampal slices and in the extracellular fluid. $A$, LTP in rat hippocampal slices was induced as described in Materials and Methods. Slices were taken at the following times after application of tetanus: 0,10 , and $30 \mathrm{sec}$ and 1, 3, 5, 30, and 60 min. Values are expressed as percentage of cGMP content in nonstimulated slices and are the mean \pm SEM of 10-27 samples per point. Values significantly different from cGMP in nonstimulated slices are as follows: ${ }^{*} p<0.05 ;{ }^{*} p<0.001 ; * * * p<0.0005 . B$, LTP in rat hippocampal slices was induced as described in Materials and Methods. The medium containing the cGMP accumulated during the first $5 \mathrm{~min}$ or during $60 \mathrm{~min}$ after application of tetanus was collected as indicated in Materials and Methods, and cGMP was determined. Values are the mean \pm SEM of five experiments. Values that are significantly different from nonstimulated samples are as follows: ${ }^{*} p<0.05 ;{ }^{*} p<0.005$.

Table 1. Effects of blocking NMDA receptors, of inhibitors of sGC, PKG, cGMP-degrading phosphodiesterase, and nitric oxide synthase, and of low-frequency stimulation of cGMP dynamics after tetanus

cGMP (\% of basal before tetanus)

\begin{tabular}{lccc} 
& \multicolumn{2}{c}{ cGMP $(\%$ of basal before tetanus $)$} \\
\cline { 2 - 4 } Treatment & \multicolumn{2}{c}{ Time after tetanus } \\
\cline { 2 - 4 } None & $10 \mathrm{sec}$ & $5 \mathrm{~min}$ & $60 \mathrm{~min}$ \\
\hline \multirow{2}{*}{$50 \mu \mathrm{M}$ APV } & $(n=20)$ & $(n=28)$ & $(n=8)$ \\
& $98 \pm 3$ & $103 \pm 8$ & $95 \pm 3$ \\
$10 \mu \mathrm{M}$ ODQ & $(n=8)$ & $(n=7)$ & $(n=8)$ \\
& $103 \pm 3$ & $102 \pm 8$ & $105 \pm 5$ \\
$10 \mu \mathrm{M}$ Rp-8-Br-cGMPS & $(n=5)$ & $(n=6)$ & $(n=7)$ \\
& $117 \pm 5^{*}$ & $137 \pm 10^{*}$ & $96 \pm 9$ \\
$2 \mu \mathrm{M}$ zaprinast & $(n=5)$ & $(n=7)$ & $(n=5)$ \\
& $139 \pm 13^{*}$ & $121 \pm 6^{*}$ & $105 \pm 6$ \\
$100 \mu \mathrm{M}$ nitroarginine & $(n=5)$ & $(n=6)$ & $(n=8)$ \\
& $96 \pm 7$ & $99 \pm 10$ & $93 \pm 6$ \\
Low-frequency stimulation & $(n=7)$ & $(n=5)$ & $(n=4)$ \\
\multirow{2}{*}{ Control without any stimulation } & $94 \pm 3$ & $96 \pm 3$ & $96 \pm 3$ \\
& $(n=6)$ & $(n=6)$ & $(n=7)$ \\
& $98 \pm 4$ & $98 \pm 5$ & $104 \pm 4$ \\
& $(n=8)$ & $(n=8)$ & $(n=8)$ \\
& & &
\end{tabular}

Experiments were performed as in Figure 2. LTP in rat hippocampal slices was induced as described in Materials and Methods. Slices were incubated with the indicated concentrations of the inhibitors for $30 \mathrm{~min}$ before application of the tetanus and taken at 0 and $10 \mathrm{sec}$ and 5 and $60 \mathrm{~min}$ after tetanus. Values are expressed as percentage of cGMP content in nonstimulated slices and are the mean \pm SEM of the indicated number of samples per point. Values significantly different from cGMP in nonstimulated slices are indicated; * $p<0.05$.

tetanus induced a rapid rise of cGMP, which reached $132 \pm 4 \%$ of basal $(n=20)$ at $10 \mathrm{sec}$. This was followed immediately by a decrease in the content of cGMP that was $92 \pm 4 \%$ of basal $(n=$ 18) after 1 min. cGMP remained significantly below basal levels for $>1 \mathrm{hr}$. At $60 \mathrm{~min}$, cGMP was $78 \pm 3 \%$ of basal $(n=14)$. As shown in Table 1, application of a low-frequency control stimulation that does not induce LTP did not affect the content of cGMP at any time.

We assessed whether the reduced content of cGMP in hip- 

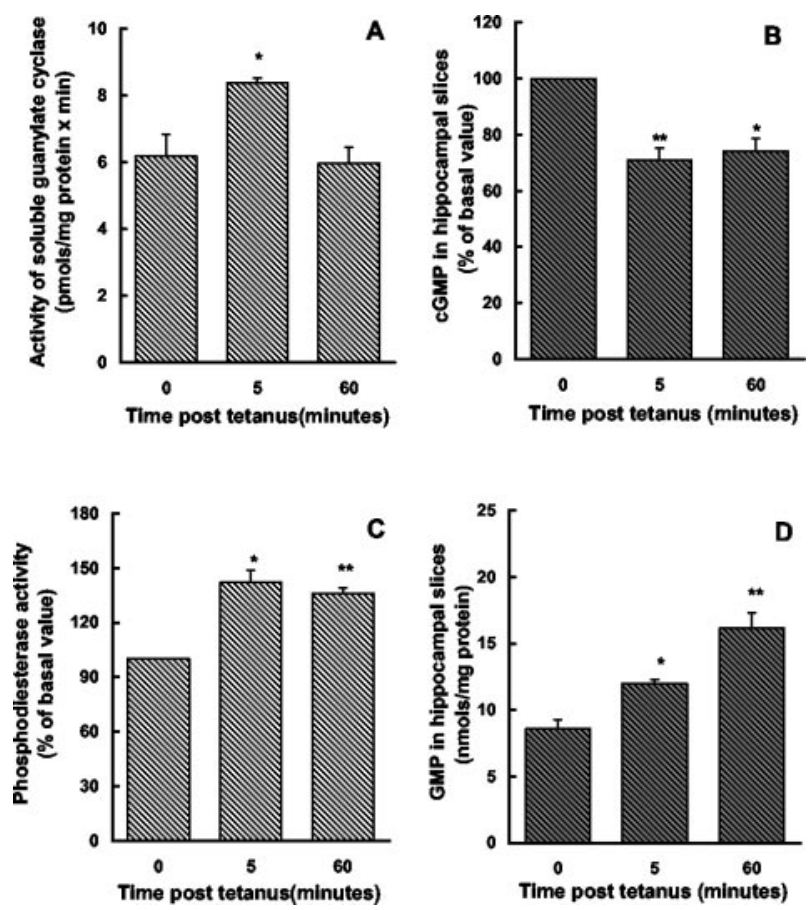

Figure 3. Effects of tetanus on the activities of sGC and cGMPdegrading phosphodiesterase and on the contents of cGMP and GMP in hippocampal slices. $A$, LTP in rat hippocampal slices was induced as described in Materials and Methods. Slices were taken at 0, 5, and $60 \mathrm{~min}$ after application of tetanus, and the activity of sGC was assayed as described in Materials and Methods. Values are the mean \pm SEM of eight experiments. Values that are significantly different $(p<0.01)$ from nonstimulated slices are indicated by asterisks. $B$, Initial content of cGMP in the slices used for the assay of sGC shown in $A$, i.e., the content of cGMP at time 0 of the guanylate cyclase assay. Values are the mean \pm SEM of eight experiments and are given as percentage of the content of cGMP in nonstimulated hippocampal slices. Values that are significantly different from nonstimulated slices are as follows: ${ }^{*} p<0.005$; ${ }^{* *} p<$ 0.001. $C$, LTP in rat hippocampal slices was induced as above, and the activity of cGMP-degrading phosphodiesterase was assayed as described in Materials and Methods. Values are the mean \pm SEM. Values that are significantly different from nonstimulated slices are as follows: ${ }^{*} p<0.001$; $* * p<0.0001 . D$, LTP in rat hippocampal slices was induced as above, and the content of GMP was determined as described in Materials and Methods. Values are the mean \pm SEM of 11 samples. Values that are significantly different from nonstimulated slices are as follows: ${ }^{*} p<0.005$; $* * p<0.0001$.

pocampal slices after application of tetanus may be caused by an enhanced release of cGMP to the extracellular medium. As shown in Figure 2B, LTP was in fact associated with a small but significant decrease in extracellular cGMP $(21 \%$ at $5 \mathrm{~min}$ and $20 \%$ at $60 \mathrm{~min}$ ).

The effects of tetanus on the activity of sGC in hippocampal slices are shown in Figure $3 A$ The activity was increased significantly, by $35 \pm 4 \%(n=7), 5$ min after tetanus and returned to basal levels at $1 \mathrm{hr}(96 \pm 10 \%$ of basal; $n=7)$.

To assess whether activation of $\mathrm{sGC}$ is mediated by activation of protein kinase $\mathrm{C}$ (PKC), we determined whether an inhibitor of this kinase (calphostin $\mathrm{C}$ ) is able to prevent tetanus-induced activation of sGC. Treatment with $60 \mathrm{~nm}$ calphostin C completely abolished tetanus-induced activation of sGC $(93 \pm 4 \%$ of basal before tetanus; $n=9$ ). The content of cGMP in the same slices in which the activity of guanylate cyclase was measured is shown in Figure $3 B$. It can be seen that cGMP was reduced significantly, by $29 \pm 4 \%$, at $5 \mathrm{~min}$ in the same samples in which the activity of

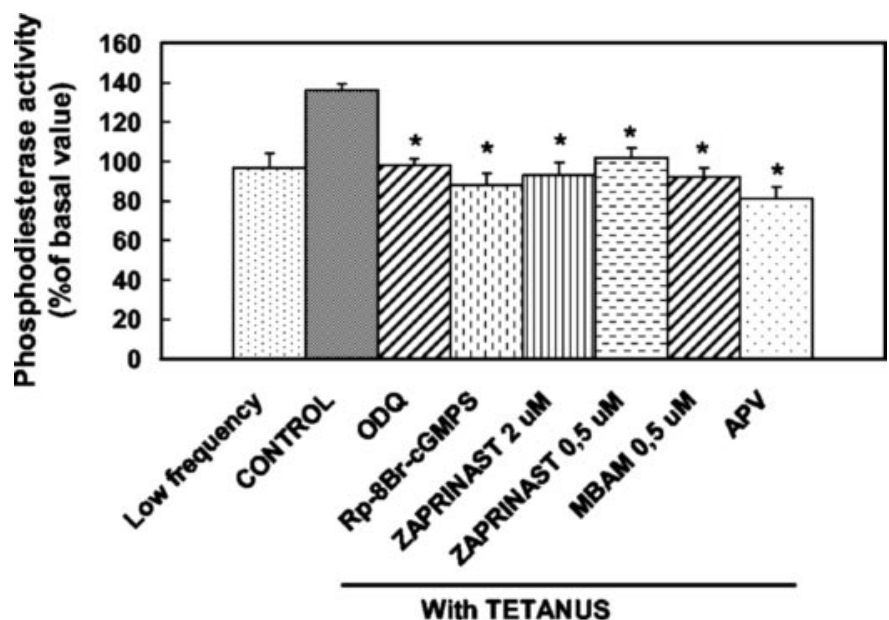

TREATMENT

Figure 4. Inhibition of sGC, of PKG, or of cGMP-degrading phosphodiesterase or blocking NMDA receptors prevented tetanus-induced activation of cGMP-degrading phosphodiesterase activity. LTP in rat hippocampal slices was induced as described in Materials and Methods. Some slices were treated with the following: ODQ, an inhibitor of sGC (10 $\mu \mathrm{M} ; n=10)$; Rp-8-Br-cGMPS, an inhibitor of cGMP-dependent protein kinase $(10 \mu \mathrm{M} ; n=11)$; zaprinast $(2 \mu \mathrm{M}, n=9 ; 0.5 \mu \mathrm{M}, n=8)$ or MBAM $(0.5 \mu \mathrm{M} ; n=7)$, inhibitors of cGMP-specific phosphodiesterase; or APV, an antagonist of NMDA receptors $(50 \mu \mathrm{M} ; n=8)$, as described in Materials and Methods. After 0 and $60 \mathrm{~min}$ of the application of tetanus, slices were taken, and the activity of cGMP-degrading phosphodiesterase was assayed as described in Materials and Methods. The activities of phosphodiesterase 60 min after tetanus are given as percentage of basal values. Values are the mean \pm SEM of 29 samples for controls and for the number of samples indicated above for each treatment. Values that are significantly different from stimulated control slices are indicated; $* p<0.0001$.

sGC is increased. This suggests that the degradation of cGMP must be also increased. To assess this possibility, we measured the effect of tetanus on the activity of cGMP-degrading phosphodiesterase in hippocampal slices.

As shown in Figure $3 C$, application of tetanus induced a significant increase in the activity of cGMP-degrading phosphodiesterase at $5 \mathrm{~min}$ (increased by $42 \pm 7 \% ; n=9$ ) and at $60 \mathrm{~min}$ (increased by $36 \pm 3 \% ; n=29$ ). The increase in the activity of the phosphodiesterase was associated with a significant increase in the product of degradation of cGMP: GMP, which was increased significantly, by $40 \pm 3 \%(n=11)$ at $5 \mathrm{~min}$ and by $88 \pm 13 \%(n=$ 8) at $60 \mathrm{~min}$ (Fig. 3D).

We subsequently assessed the mechanism by which application of tetanus may lead to activation of cGMP-degrading phosphodiesterase. This enzyme is modulated by phosphorylation by PKG (see Discussion), which in turn is activated by cGMP, the product of sGC. We therefore supposed that the pathway leading from tetanus to activation of cGMP-degrading phosphodiesterase might involve activation of sGC, leading to increased content of cGMP, which would activate PKG, which, in turn, will activate cGMP-degrading phosphodiesterase. To assess whether this is in fact the pathway leading to activation of phosphodiesterase, we tested whether inhibiting the different steps of the pathway prevents the activation of the phosphodiesterase induced by tetanus. Inhibition of sGC with ODQ completely prevented the activation of phosphodiesterase (Fig. 4). Application of tetanus to control slices increased the activity of the cGMP-degrading phosphodi- 

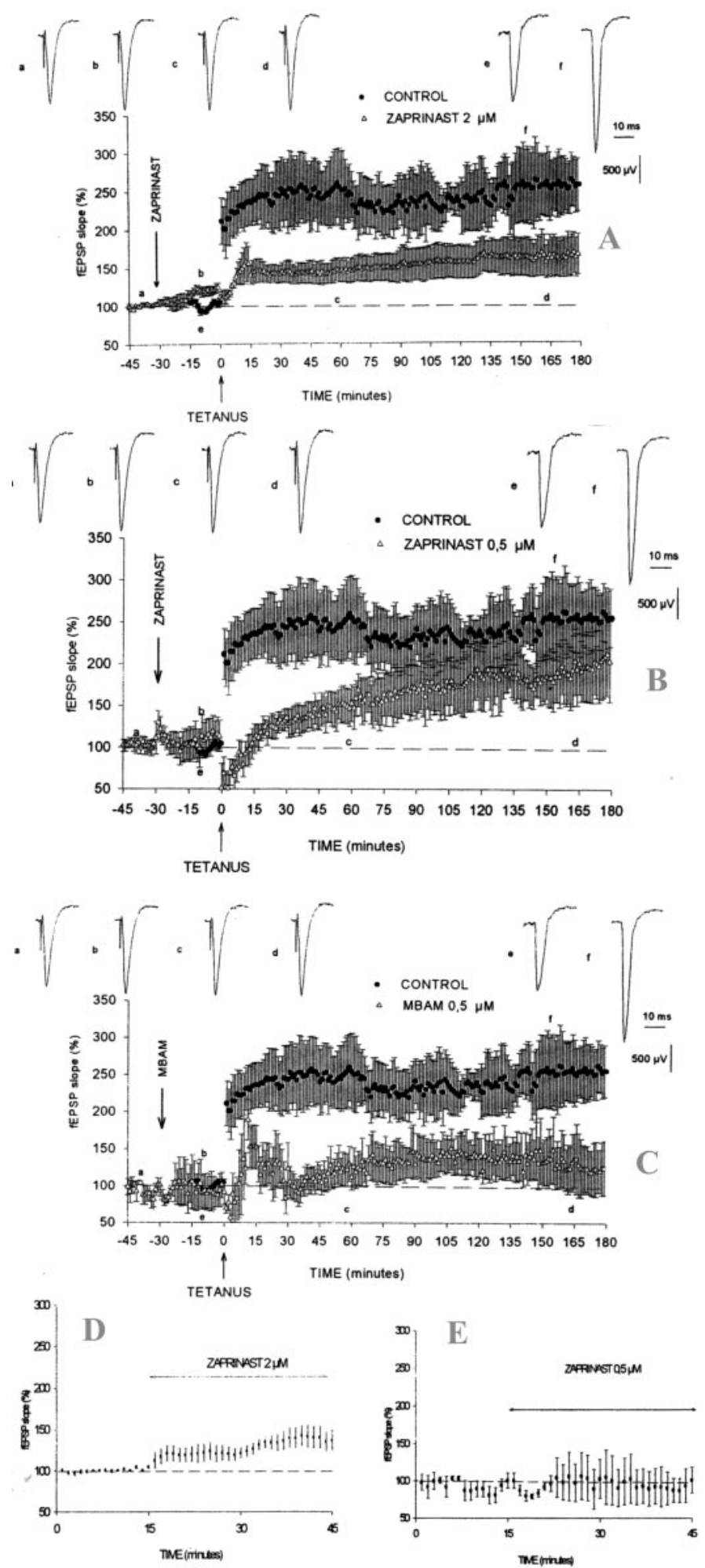

Figure 5. Inhibition of cGMP-degrading phosphodiesterase impairs LTP induction in hippocampal slices. LTP in rat hippocampal slices was induced as described in Materials and Methods. Schaffer collateralcommissural pathways were stimulated with electrical pulses, and, at the time indicated by the arrow, tetanus was applied. Basal fEPSPs were obtained before drug application and normalized to $100 \%$. Filled circles show the nondecremental LTP induced by tetanus in control slices (mean $\pm \mathrm{SEM} ; n=7$ ). Triangles show the fEPSP in slices treated with the selective inhibitors of cGMP-specific phosphodiesterase: $2 \mu \mathrm{M}$ zaprinast in $A(n=7)$; $0.5 \mu \mathrm{M}$ zaprinast in $B(n=5)$; or $0.5 \mu \mathrm{M}$ MBAM in $C(n=$ esterase by $36 \pm 3 \%(n=29)$. However, if the slices are previously perfused with ODQ to inhibit sGC, the activity of phosphodiesterase did not increase after application of tetanus and remained at $98 \pm 3 \%(n=10)$ of basal activity (Fig. 4$)$.

The increase in the activity of phosphodiesterase was also prevented completely in slices treated with Rp-8-Br-cGMPS (10 $\mu \mathrm{M})$ to inhibit PKG (Fig. 4). Under these conditions, the activity of phosphodiesterase remained at $88 \pm 6 \%$ of basal $(n=11)$. Perfusion with zaprinast $(0.5$ or $2 \mu \mathrm{M})$ or with MBAM $(0.5 \mu \mathrm{M})$, inhibitors of cGMP-degrading phosphodiesterase, also completely prevented the increase in the activity of phosphodiesterase (Fig. 4). Application of low-frequency control stimulation did not induce an increase in phosphodiesterase activity (Fig. 4), thus confirming that this increase is caused by tetanus.

To assess whether this guanylate cyclase-cGMP-dependent protein kinase-cGMP-degrading phosphodiesterase is necessary for proper induction of LTP, we assessed whether blocking the pathway impairs induction of LTP. As shown in Figure 1, inhibition of sGC with ODQ impairs induction of LTP. It has been reported in the literature that inhibition of PKG impairs LTP (see Discussion). As shown in Figure 5, inhibition of cGMP-degrading phosphodiesterase with zaprinast or with MBAM also impairs the induction of LTP.

These results indicate that application of tetanus to induce LTP activates the sGC-cGMP-dependent protein kinase-cGMPdegrading phosphodiesterase pathway and that activation of this pathway is necessary for proper induction of LTP.

The effects of the inhibition of the different steps of this pathway on cGMP dynamics are shown in Table 1. Inhibition of sGC with ODQ completely prevents both the initial increase in cGMP at $10 \mathrm{sec}$ and the subsequent decrease at 5 or $60 \mathrm{~min}$. Inhibition of PKG with Rp-8-Br-cGMPS did not prevent the initial increase of cGMP but rather maintained the increase up to $5 \mathrm{~min}$ and prevented the decrease in cGMP at 5 or $60 \mathrm{~min}$. Inhibition of cGMP-degrading phosphodiesterase with zaprinast had the same effects as inhibition of cGMP-dependent protein kinase, did not prevent the initial increase of cGMP but rather maintained the increase up to $5 \mathrm{~min}$, and prevented the decrease in cGMP at 5 or 60 min. Blocking NMDA receptors with APV or inhibition of nitric oxide synthase with nitroarginine prevented all of the changes in cGMP, both the initial increase in cGMP at $10 \mathrm{sec}$ and the subsequent decrease at 5 or $60 \mathrm{~min}$ (Table 1). Moreover, as shown in Figure 4, blocking NMDA receptors with APV also prevented the activation of phosphodiesterase induced by tetanus.

As a control to assess whether ODQ or zaprinast may be affecting the presynaptic release machinery, we studied the effects of these inhibitors on paired-pulse facilitation. ODQ or zaprinast at $0.5 \mu \mathrm{M}$ did not affect it at all, whereas zaprinast at $2 \mu \mathrm{M}$ reduced the paired-pulse facilitation ratio when the stimulus was given at 50 or 125 msec intervals but not at other interstimulus interval.

\section{$\leftarrow$}

4). Zaprinast or MBAM was added 30 min before application of tetanus (indicated by arrow) and maintained throughout the experiment. Raw evoked field potentials at the indicated times are indicated by letters: $a, b$, $c, d$, zaprinast; $e, f$, control. Calibration: $500 \mu \mathrm{V}, 10 \mathrm{msec}$. $D$, Effect of 2 $\mu \mathrm{M}$ zaprinast on field EPSP without application of tetanus (mean \pm SEM; $n=7)$. The fEPSP amplitude was significantly different from controls until 14 min (Student's $t$ test for unpaired data; $p \leq 0.05$ ). $E$, Effect of 0.5 $\mu \mathrm{M}$ zaprinast on field EPSP without application of tetanus (mean \pm SEM; $n=6)$. Values are not different from basal. 


\section{DISCUSSION}

Under the conditions used, sGC inhibition with ODQ impaired LTP but did not affect low-frequency stimulation-induced postsynaptic potential (Fig. 1). This agrees with reports from Boulton et al. (1995) and Lu et al. (1999). Zhuo et al. (1994) found that LY83583 (6-anilino-5,8-quinolinequinone), another sGC inhibitor, also impairs LTP. In contrast, Kleppisch et al. (1999) and Wu et al. (1998) did not find any effect of ODQ on LTP. The reasons for the different effects of ODQ in these studies are unclear. Kleppisch et al. (1999) used mice, and the present study used rats. The different schedule of ODQ administration could also be responsible for the differences (Son et al., 1998). To further confirm the role of sGC in LTP, we assessed whether NS 2028, another inhibitor of sGC, impairs LTP. As shown in Figure $1 B$, this was the case, confirming that sGC inhibition impairs LTP, indicating a role for $\mathrm{sGC}$ and cGMP in LTP.

We studied the effects of tetanus in inducing LTP on cGMP content in hippocampal slices. Tetanus induced a rapid increase in cGMP (Fig. $2 A$ ), reaching a maximum after $10 \mathrm{sec}$. This transient increase was followed by a rapid decrease. cGMP returned to basal values $30 \mathrm{sec}$ after tetanus, decreased to values significantly below basal values after $5 \mathrm{~min}$, and remained lower than basal after 60 min. The transient cGMP increase agrees with a previous report by Chetkovich et al. (1993). Changes in cGMP are caused by tetanus and did not occur for low-frequency control stimulation (Table 1). The initial cGMP increase should be caused by sGC activation and the subsequent decrease by phosphodiesterase activation or by cGMP release to the extracellular fluid.

To assess these possibilities, we measured sGC activity after tetanus. The activity was increased significantly 5 min after tetanus but was not different from basal after 60 min (Fig. 3A), indicating that tetanus induces a transient sGC activation, followed by a rapid return to basal activity.

Nitric oxide-induced sGC activation may explain most of the initial increase in cGMP. However, this is not the only mechanism by which tetanus activates sGC. The transient nitric oxide increase induced by tetanus cannot be detected in the in vitro assay of sGC activity because nitric oxide is no longer present. The fact that the activity of sGC in vitro is altered suggests that there is some covalent modification of the enzyme remaining in the in vitro assay. A good candidate for this modification is phosphorylation. sGC is phosphorylated (and activated) by PKC (Zwiller et al., 1985; Louis et al., 1993) and by cAMP-dependent protein kinase (Zwiller et al., 1981). PKC is activated in LTP (Akers et al., 1986; Hu et al., 1987; Lovinger et al., 1987). It is possible that $\mathrm{sGC}$ phosphorylation by $\mathrm{PKC}$ may contribute to its activation in LTP. As shown in Results, PKC inhibition with calphostin $\mathrm{C}$ abolished tetanus-induced sGC activation. However, the prevention of sGC activation by calphostin $\mathrm{C}$ may be a result of an effect on NMDA receptors (López-Molina et al., 1993), and it is not possible to definitely assign the prevention to decreased PKC-mediated phosphorylation of sGC.

The decrease in cGMP observed after the fast transient initial increase may be caused by enhanced cGMP release to the extracellular space or by activation of phosphodiesterase, which degrades cGMP. Tetanus did not result in increased cGMP release to the extracellular space (Fig. 2B). The decrease in cGMP may be attributed to increased activity of cGMP-degrading phosphodiesterase (Fig. $3 C$ ). The increase in GMP (the product of degradation of cGMP) shown in Figure $3 D$ confirms that cGMPdegrading phosphodiesterase is activated after tetanus.
We subsequently studied the mechanism by which tetanus leads to activation of phosphodiesterase. As discussed above for sGC, the fact that activation of cGMP-degrading phosphodiesterase is detected in vitro indicates that tetanus induces covalent modification of the enzyme that remains during in vitro assays. Phosphorylation is also a good candidate for this modification of phosphodiesterase. cGMP-specific phosphodiesterase is phosphorylated by PKG in vitro (Thomas et al., 1990) and in vivo (Wyatt et al., 1998; Corbin et al., 2000). This phosphorylation results in phosphodiesterase activation (Wyatt et al., 1998; Corbin et al., 2000), suggesting that phosphorylation of cGMP-specific phosphodiesterase by PKG may be involved in physiological feedback regulation of cGMP levels.

To assess whether tetanus-induced activation of cGMPdegrading phosphodiesterase is mediated by phosphorylation by PKG, we tested whether PKG inhibition with Rp-8-cGMPS prevents phosphodiesterase activation. As shown in Figure 4, this was the case. Moreover, phosphodiesterase activation is also prevented by sGC inhibition. These results indicate that tetanus leads to transient activation of sGC, leading to an increased content of cGMP, which activates PKG, which, in turn, activates cGMP-degrading phosphodiesterase.

This process is initiated by NMDA receptor activation, leading to nitric oxide synthase activation and formation of nitric oxide, which activates sGC. Blocking NMDA receptors with APV or inhibiting nitric oxide synthase with nitroarginine prevents tetanus-induced cGMP changes (Table 1). Blocking NMDA receptors also prevents tetanus-induced phosphodiesterase activation. In the presence of APV, tetanus leads to a slight decrease in phosphodiesterase activity after $60 \min (81 \pm 6 \%$; $p=0.013)$. sGC inhibition with ODQ prevents all subsequent cGMP changes (Table 1), indicating that sGC activation and transient cGMP increase are necessary to activate $\mathrm{PKG}$ and phosphodiesterase.

Inhibition of PKG or of phosphodiesterase did not prevent the initial rise in cGMP but prevented the decrease in cGMP at 5 and 60 min (Table 1), indicating that PKG activation is necessary for subsequent phosphodiesterase activation. Moreover, in the presence of inhibitors of PKG or phosphodiesterase, the initial increase in cGMP is maintained at $5 \mathrm{~min}$, thus confirming that the decrease at $5 \mathrm{~min}$ in the absence of inhibitors is caused by PKG-mediated activation of cGMP-degrading phosphodiesterase.

Activation of this sGC-PKG-cGMP-degrading phosphodiesterase pathway is necessary for proper LTP induction, as indicated by the fact that inhibition of any step of the pathway impairs LTP. As shown in Figure 1 and reported by other authors (see above), sGC inhibition impairs LTP.

PKG inhibition also impairs LTP. Zhuo et al. (1994) and Blitzer et al. (1995) showed that PKG inhibitors impair LTP in hippocampal slices. Arancio et al. (2001) showed that injecting a peptide inhibitor of PKG blocked long-lasting potentiation in hippocampal neurons. This indicates that PKG activation is required for induction of LTP.

Inhibition of cGMP-degrading phosphodiesterase with zaprinast or MBAM impairs LTP in hippocampal slices (Fig. 5). To assess whether ODQ or zaprinast affects the presynaptic release machinery, we assessed whether they affect paired-pulse facilitation. ODQ did not affect this process or post-tetanic potentiation (Fig. 1), indicating that sGC inhibition does not affect presynaptic events and that all its effects are a result of inhibition of postsynaptic sGC and of the guanylate cyclase-PKG-PDE pathway.

Conversely, zaprinast at $2 \mu \mathrm{M}$ inhibits post-tetanic potentiation (Fig. 5) and decreases paired-pulse facilitation ratio, suggesting 
that, in addition to its postsynaptic effects on PDE, zaprinast at 2 $\mu \mathrm{M}$ also affects presynaptic events. It has been suggested that a zaprinast-induced increase of presynaptic cGMP activates cGMP-dependent ion channels, increasing calcium entry into presynaptic terminals and neurotransmitter release (Arancio et al., 1995; Kuzmiski and MacVicar, 2001). Increased glutamate release may explain the slight increase in fEPSP induced by $2 \mu \mathrm{M}$ zaprinast before tetanus (Fig. 5), as well as the "occlusion" of post-tetanic potentiation by zaprinast and the reduction in paired-pulse facilitation ratio. These presynaptic effects of $2 \mu \mathrm{M}$ zaprinast occur in parallel to its postsynaptic effects on PDE.

The results using $2 \mu \mathrm{M}$ zaprinast agree with those of Arancio et al. (1995) and Kuzmiski and MacVicar (2001). However, other authors reported different effects. Wu et al. (1998) and Santschi et al. (1999) reported that $20 \mu \mathrm{M}$ zaprinast induces long-term depression. Santschi et al. (1999) did not find any effect of zaprinast on paired-pulse facilitation, whereas Wu et al. (1998) found an effect attributed to decreased neurotransmitter release. The difference between these studies and the present work may be a result of the different concentrations of zaprinast ( 20 vs $2 \mu \mathrm{M})$ and/or, in the case of Wu et al. (1998), of the different hippocampal area studied (dentate gyrus vs CA1).

We subsequently used zaprinast at a concentration that does not affect presynaptic events. Zaprinast at $0.5 \mu \mathrm{M}$ did not affect pairedpulse facilitation or baseline synaptic transmission (Fig. 5), indicating that, at $0.5 \mu \mathrm{M}$, zaprinast does not affect presynaptic events.

We tested whether this concentration of zaprinast $(0.5 \mu \mathrm{M})$, which does not affect baseline synaptic transmission or another inhibitor of the cGMP-degrading phosphodiesterase (MBAM), impairs LTP. Under these conditions, tetanus-induced activation of phosphodiesterase was completely prevented (Fig. 4), and induction of LTP was impaired (Fig. 5), confirming that activation of cGMP-degrading phosphodiesterase is required for proper LTP induction.

The results reported show clearly that tetanus leads to transient activation of $\mathrm{sGC}$ (mediated by activation of NMDA receptors and nitric oxide synthase), leading to increased cGMP, which activates $\mathrm{PKG}$, which, in turn, activates cGMP-degrading phosphodiesterase. Moreover, activation of this sGC-PKG-cGMPdegrading phosphodiesterase pathway is necessary for proper LTP induction.

\section{REFERENCES}

Akers RF, Lovinger DM, Colley PA, Linden DJ, Routtenberg A (1986) Translocation of protein kinase $\mathrm{C}$ activity may mediate hippocampal long-term potentiation. Science 231:587-589.

Arancio O, Kandel ER, Hawkins RD (1995) Activity-dependent longterm enhancement of transmitter release by presynaptic $3^{\prime}, 5^{\prime}$-cyclic GMP in cultured hippocampal neurons. Nature 376:74-80.

Arancio O, Antonova I, Gambaryan S, Lohmann SM, Wood JS, Lawrence DS, Hawkins RD (2001) Presynaptic role of cGMP-dependent protein kinase during long-lasting potentiation. J Neurosci 21:143-149.

Baginski ES, Foá PP, Zak B (1974) Glucose-6-phosphatase. In: Methods of enzymatic analysis (Bergmeyer HU, ed), pp 876-880. Weinheim, Germany: Verlag Chemie Weinheim.

Beltman J, Sonnenburg WK, Beavo JA (1993) The role of protein phosphorylation in the regulation of cyclic nucleotide phosphodiesterases. Mol Cell Biochem 127-128:239-253.

Blitzer RD, Wong T, Nouranifar R, Iyengar R, Landau EM (1995) Postsynaptic cAMP pathway gates early LTP in hippocampal CA1 region. Neuron 15:1403-1414.

Böhme GA, Bon C, Stutzmann JM, Doble A, Blanchard JC (1991) Possible involvement of nitric oxide in long-term potentiation. Eur J Pharmacol 199:379-381.

Boulton CL, Southam E, Garthwaite J (1995) Nitric oxide-dependent long-term potentiation is blocked by a specific inhibitor of soluble guanylyl cyclase. Neuroscience 69:699-703.

Chetkovich DM, Klann E, Sweatt JD (1993) Nitric oxide synthase- independent long-term potentiation in area CA1 of hippocampus. NeuroReport 4:919-922.

Corbin JD, Turko IV, Beasley A, Francis SH (2000) Phosphorylation of phosphodiesterase- 5 by cyclic nucleotide-dependent protein kinase alters its catalytic and allosteric cGMP-binding activities. Eur J Biochem 267:2760-2767.

Doyle C, Hölscher C, Rowan MJ, Anwyl R (1996) The selective neuronal NO synthase inhibitor 7-nitroindazole blocks both long-term potentiation and depotentiation of field EPSPs in rat hippocampal CA1 in vivo. J Neurosci 16:418-424.

Haley JE, Malen PL, Chapman PF (1993) Nitric oxide synthase inhibitors block long term potentiation induced by weak but not strong tetanic stimulation at physiological brain temperatures in rat hippocampal slices. Neurosci Lett 160:85-88.

Hu GY, Hvalby O, Walaas SI, Albert KA, Skjeflo P, Andersen P, Greengard P (1987) Protein kinase C injection into hippocampal pyramidal cells elicits features of long term potentiation. Nature 328:426-429.

Keppler D, Kaiser W (1985) Guanosine-5-triphosphate, guanosine-5diphosphate and guanosine-5'-monophosphate. In: Methods of enzymatic analysis (Bergmeyer HU, ed), pp 409-418. Weinheim, Germany: Verlag Chemie Weinheim.

Kleppisch T, Pfeifer A, Klatt P, Ruth P, Montkowski A, Fässler R, Hofmann F (1999) Long-term potentiation in the hippocampal CA1 region of mice lacking cGMP-dependent kinases is normal and susceptible to inhibition of nitric oxide synthase. J Neurosci 19:48-55.

Kuzmiski JB, MacVicar BA (2001) Cyclic nucleotide-gated channels contribute to the cholinergic plateau potential in hippocampal CA1 pyramidal neurons. J Neurosci 21:8707-8714.

López-Molina L, Boddeke H, Muller D (1993) Blockade of long-term potentiation and of NMDA receptors by the protein kinase $\mathrm{C}$ antagonist calphostin C. Arch Pharmacol 348:1-6.

Louis JC, Revel MO, Zwiller J (1993) Activation of soluble guanylate cyclase through phosphorylation by protein kinase C in intact PC12 cells. Biochim Biophys Acta 1177:299-306.

Lovinger DM, Wong KL, Murakami K, Routtenberg A (1987) Protein kinase C inhibitors eliminate hippocampal long-term potentiation. Brain Res 436:177-183.

Lu Y, Kandel ER, Hawkins RD (1999) Nitric oxide signaling contributes to late-phase LTP and CREB phosphorylation in the hippocampus. J Neurosci 19:10250-10261.

Montoliu C, Llansola M, Kosenko E, Corbalán R, Felipo V (1999) Role of cyclic GMP in glutamate neurotoxicity in primary cultures of cerebellar neurons. Neuropharmacology 38:1883-1891.

Muñoz MD, Monfort P, Gaztelu JM, Felipo V (2000) Hyperammonemia impairs NMDA receptor-dependent long-term potentiation in the CA1 of rat hippocampus in vitro. Neurochem Res 25:437-441.

O'Dell TJ, Hawkins RD, Kandel ER, Arancio O (1991) Tests of the roles of two diffusible substances in long-term potentiation: evidence for nitric oxide as a possible early retrograde messenger. Proc Natl Acad Sci USA 88:11285-11289.

Santschi L, Reyes-Harde M, Stanton PK (1999) Chemically induced, activity-independent LTD elicited by simultaneous activation of PKG and inhibition of PKA. J Neurophysiol 82:1577-1589.

Schuman EM, Madison DV (1991) A requirement for the intercellular messenger nitric oxide in long-term potentiation. Science 254:1503-1506.

Schuman EM, Meffert MK, Schulman H, Madison DV (1994) An ADPribosyl transferase as a potential target for nitric oxide action in hippocampal long-term potentiation. Proc Natl Acad Sci USA 91:1195811962.

Selig DK, Segal MR, Liao D, Malenka R, Malinow R, Nicoll RA, Lisman $\mathrm{JE}$ (1996) Examination of the role of cGMP in long-term potentiation in the CA1 region of the hippocampus. Learn Mem 3:42-48.

Son H, Lu Y, Zhuo M, Arancio O, Kandel E, Hawkins R (1998) The specific role of cGMP in hippocampal LTP. Learn Mem 5:231-245.

Thomas MK, Francis SH, Corbin JD (1990) Substrate- and kinasedirected regulation of phosphorylation of a cGMP-binding phosphodiesterase by cGMP. J Biol Chem 265:14971-14978.

Wu J, Wang Y, Rowan MJ, Anwyl R (1998) Evidence for involvement of the cGMP-protein kinase $G$ signaling system in the induction of longterm depression, but not long-term potentiation, in the dentate gyrus in vitro. J Neurosci 18:3589-3596.

Wyatt TA, Naftilan AJ, Francis SH, Corbin JD (1998) ANF elicits phosphorylation of the cGMP phosphodiesterase in vascular smooth muscle cells. Am J Physiol 274:448-455.

Zhuo M, Hu Y, Schultz C, Kandel ER, Hawkins RD (1994) Role of guanylyl cyclase and cGMP-dependent protein kinase in long-term potentiation. Nature 368:635-639.

Zucker RS (1989) Short-term synaptic plasticity. Annu Rev Neurosci 12:13-31.

Zwiller J, Revel MO, Basset P (1981) Evidence for phosphorylation of rat brain guanylate cyclase by cyclic-AMP-dependent protein kinase. Biochem Biophys Res Commun 101:1381-1387.

Zwiller J, Revel MO, Malviya AN (1985) Protein kinase C catalyzes phosphorylation of guanylate cyclase in vitro. J Biol Chem 260:13501353. 